\title{
STUDY ON MATHEMATICAL MODEL IN SIMULATING CYMBOPOGON WINTERIANUS ESSENTIAL OIL EXTRACTION BY STEAM DISTILLATION
}

\author{
Nik 'Amirah Farhana Nik Ahmad Lutfi', Mohd Farid Atan², Nazeri Abdul Rahman', \\ Shanti Faridah Salleh ${ }^{4}$ and Noraziah Abdul Wahab ${ }^{5}$ \\ 1,2,3,4,5 Department of Chemical Engineering and Energy Sustainability, \\ Universiti Malaysia Sarawak, Kota Samarahan, Sarawak, Malaysia. \\ ${ }^{1}$ Email:nikamirahfarhana@gmail.com, ${ }^{2}$ Email:amfarid@unimas.my, \\ ${ }^{3}$ Email:arnazeri@unimas.my, ${ }^{4}$ Email:sshanti@unimas.my, ${ }^{5}$ Email:anoraziah@unimas.my
}

\begin{abstract}
The main objective of this study is to improve the mathematical modelling of Cymbopogon winterianus essential oil extraction by steam distillation proposed by Cassel and Vargas by minimum 5\% error reduction. Two process variable of steam distillation which are extraction time and raw material state (dry or natural) has been optimized by using factorial experimental planning to obtain high yields of citronella essential oil from twig and leaves of lemongrass species Cymbopogon winterianus (C.winterianus). The optimal condition for maximum yield (0.942\%) were found to be an extraction time, $4 \mathrm{hr}$, state, natural plant. The study of Cassel and Vargas was subsequently continued with five proposed kinetics model of the extraction process. The modelling of the extraction process is optimized by using one adjustable parameter of the model and the adequacy of the fit of the models to the experimental data are analyzed by using three statistical criteria that are correlation coefficient $(r)$, the root mean square error (RMSE) and the mean relative deviation modulus $(E)$. The result has shown that the mathematical model developed by Ana based on mass transfer fundamentals is the optimum mathematical model for the extraction of Cymbopogon winterianus essential oil by steam distillation.
\end{abstract}

Keywords: Essential Oils, Cymbopogon winterianus essential oil, Optimization of mathematical model of extraction of citronella essential oils

\section{Introduction}

Cymbopogon winterianus is commonly known as Citronella. Citronella Grass and Java Citronella grass is a lemongrass species that is believed to have originated from Cymbopogon nardus that often referred to Ceylonese, a Sri Lankan commercial citronella. Cymbopogon winterianus was named after the Winter whom presented the plant as a separate species in 19th century. It is later than introduced to Indonesia and commercially known as Javanese citronella. The plant later was further introduced to India in 1959 [1].

Essential oils are subtle, natural, aromatic and volatile compounds which are extracted from the flower, seeds, leaves, stems, bark and roots of herbs [2]. As agreed by Tajidin et al (2012), essential oils are natural products which can be extracted from plants. They were formed through mixture of varied and complex volatile chemical compounds with high proportion of terpene

Manuscript History:

Received 4 August, 2015, Revised 21 March, 2016, Accepted 22 March, 2016, Published 31 March, 2016

e-ISSN 2289-7771

Copyright @ 2016 JASPE 
associated with aldehyde, ketone and alcohols. The different mixtures of the chemical then were deposited in different structure of the plant [3]

Essential oil can be extracted traditionally by hydrodistillation, steam distillation, or solvent extraction [4]. Kabuba (2013) also stated that essential oils derived from aromatic plant are typically extracted by steam distillation as this method is simple and relatively inexpensive process. The essential oil in the plant is removed by steam of water vapour and can be separate easily in the next phase [5]. The aromatic industry often employed this extraction method as it is cheaper than advanced methods such as supercritical fluid extraction (SFE). The proportion of different essential oil extracted by steam distillation in the industry is $93 \%$ and the remaining $7 \%$ employed other extraction methods such as SFE and microwaves extraction [5]. This method is also preferred by Amenaghawon et al (2014) because steam distillation is flexible, versatile, do not lead to decomposition of essential oils and provides the possibility of operating with small volumes [6].

Essential oils played an important role in the personal and social hygiene of mankind in terms of their application in cosmetics, toiletries, medicinal formulation, surface coatings and aroma therapy [7]. Essential oils have been largely applied in various areas due to their natural properties which exhibit antibacterial, antifungal, insecticidal, antiviral and anti-herbivore characteristics. To date, approximately 3000 essential oils are known at the and 200 of the essential oils are commercially important especially in pharmaceutical, agronomic, sanitary, food, cosmetics and perfume industries [4].

Citronella oil is a clear liquid that possesses strong lemon-like odour and pale yellow colour. The total amount of essential oils present in lemongrass varies between $0.28 \%$ and $1.4 \%$. Maximum recovered recorded is at 3\% [6]. Citronella oil can be fractionated into three major constituent chemicals which are citronellal, citronelol and geraniol. The three major constituent chemicals are used commercially in the industry for many purposes such as soaps, sprays, disinfectants and polishes [1]. The major constituent of the essential oil is citral which is more than $75 \%$ by weight of the essential oil [4]. Citral is the natural combination of two isomeric aldehydes namely isomers geranial $(\alpha$-citral) and neral ( $\beta$-citral). Other unusual active components are limonene, geraniol, citronella and $\beta$-myrcene [3]. The essential oil quality is judged by its citral content and the oil solubility in alcohol. The citronella essential oil can be in reddish-yellow to reddish brown colour with strong lemon odour properties. It is used in perfume, cosmetics and soap. Citronella essential oil serves as important raw material to pharmaceutical preparation such as pain balm, disinfectants and mosquito-repellent creams [4].

Mathematical modelling of steam distillation is considered an inevitable step to project industrial plants that have good operational conditions. The advantage of using mathematical models is the process can be simulated without running the experimental procedures in order to know the extraction process behaviour. Therefore the mathematical model allows alternative strategies to be tested in order to evaluate the selection of the process variable conditions [9]. Another advantage of having a well-accepted mathematical model is its usefulness in the development of up-scaling procedures from laboratory to pilot and then to industrial scale [5]. By modelling the kinetics of distillation or any other process, it can contribute not only toward the fundamental understanding of the process but can also contribute towards better control and higher efficiency [10].

Mathematical modelling is flexible as it can be varied from simple mathematical model to complex mathematical model. Many researchers construct their own mathematical model by using various physical laws with the aid of mathematical software such as Matlab, ANOVA and Designer Software 6.0.6. Benyoussef et al (2002) modelled the steam distillation of essential oil from coriander by using two diffusion models that take into account both diffusion and transfer of species [11] whereas Cassel and Vargas modelled the steam distillation of lemon grass using a model based on Fick's law steady state for one-dimensional rectangular geometry [12]. On the other hand, Ha et al modelled the extraction of essential oil from lemon grass stems by using two-factor interaction model and a linear mode in terms of coded variables for the extraction of essential oil from lemon grass stem [13]. 


\section{Laboratory experiment}

In the previous research done by Cassel and Vargas (2006) in their research "Experiments and Modelling of the Cymbopogon winterianus Essential Oil Extraction by Steam Distillation", a laboratory experiments were conducted to obtain a real data on the extraction of the Cymbopogon winterianus essential oil. The data obtained from this laboratory scale experiment were used as a benchmark and reference in developing the mathematical model of the process [12].

\subsection{Material and method}

The experiment was conducted by using $0.04 \mathrm{~kg}$ of citronella leaves samples with the average thickness of $5.25 \times 10-4 \mathrm{~m}$. The total extraction time is 114 min with the maximum yield of $1.02 \mathrm{~g}$ of essential oil. The principal compounds of citronella essential oil found are citronellal, citronellole, geraniole, geranyl acetate and $\alpha$-cadinol. The experimental data from steam distillation for citronella is shown in Table 1 [12].

\subsection{Degree of extraction}

The degree of extraction, e is found by using the experimental data obtained and the mathematical formula (1) [12].

$$
\mathrm{e}(\mathrm{t})=\frac{\mathrm{m}_{\mathrm{A}}(\mathrm{t})}{\left.\mathrm{m}_{\mathrm{A}(\infty)}\right)}
$$

Where $e(t)$ is the degree of extraction time at time $t, m_{A}(t)$ is the mass of citronella essential oil in gram unit extracted at time $t$ and $m_{A}(\infty)$ is the maximum mass of citronella essential oil in gram unit extracted at the end of the experiment. The value of $e(t)$ calculated is shown in Table 1.

\subsection{Yield of citronella essential oil}

The yield of the extracted citronella essential oil is calculated by using the experimental data obtained and the mathematical formula (2) [12].

$$
\text { Yield }=\frac{m_{\mathrm{A}}(\mathrm{t})}{\mathrm{m}_{\mathrm{g}}}
$$

Where $m_{A}(t)$ is the mass of citronella essential oil in gram unit extracted at time $t$ and $m_{S}$ is the mass of the citronella leaves sample in gram unit used at the beginning of the experiment. The extracted citronella essential oil yield calculated is shown in Table 1.

\section{Kinetic model proposed}

Models derived from Fick's second law of diffusion are frequently used to describe the kinetics of the extraction of different constituents from plant material. Simplified model and secondorder kinetic model is also often used depending on the type of extraction method used and plant material itself [14]. A physical model that is derived based on simultaneous washing and diffusion to describe the system kinetics of essential oil extraction is often known second order kinetics while simplified model that assume either instantaneous washing followed by diffusion or diffusion with no washing is known as first order kinetics [15]. The main goal is to compare the first-order kinetic model 
and second-order kinetics model and suggest the most optimum mathematical model for Cymbopogon winterianus Essential Oil Extraction by Steam Distillation.

\subsection{Cassel and Vargas (2006) method}

In the research by Cassel and Vargas (2006) "Experiments and Modeling of the Cymbopogon winterianus Essential Oil Extraction by Steam Distillation", a mathematical model based on Fick's law in steady-state for one-dimensional geometry was developed and used to predict the yield of citronella essential oil extracted.

In the mathematical model, the assumptions made are:

1. At the beginning of the process the soluble constituent's concentration is homogenous and constant for the entire particle in the plant.

2. The steam carries out all the essential oil at the boundaries thus making the oil concentration at the boundaries very small $\left(c_{A}=0\right)$.

The mathematical formulation is express as in (3) shown below [12].

$$
\frac{\partial^{\mathrm{z}} \mathrm{c}_{\mathrm{A}}}{\partial \mathrm{x}^{2}}=\frac{1}{\mathrm{D}} \frac{\partial \mathrm{c}_{\mathrm{A}}}{\partial \mathrm{t}} \text { in } 0 \leq \mathrm{x} \leq \mathrm{L}
$$

With the initial condition stated as in (4) [12]

$$
\mathrm{c}_{\mathrm{A}}=\mathrm{c}_{\mathrm{AO}} \text { in } \mathrm{t}=0
$$

And the boundary conditions showed as in (5) and (6) [12]

$$
\begin{aligned}
& c_{\mathrm{a}}=0 \text { in } \mathrm{x}=0 \\
& \mathrm{c}_{\mathrm{a}}=0 \text { in } \mathrm{x}=\mathrm{L}
\end{aligned}
$$

Where $c_{A}$ is the concentration at time $t, c_{A O}$ is the initial concentration at time $t=0, L$ is the thickness of the plant leaves ad D is the effective diffusion coefficient. By using separation variable technique the following solution (7) till (8) was established [12].

$$
\begin{aligned}
& c_{A}(x, t)=\sum_{n=1}^{\infty} \frac{4 c_{A O}}{n \pi} \operatorname{sen}\left(\beta_{n} x\right) e^{-D \beta_{n}^{2} t} \\
& \beta_{n}=\frac{n \pi}{L}
\end{aligned}
$$

With $n=1,2,3 \ldots$ The mass flow as function of time was obtained from mass flux at boundary multiplied by the normal surface area which resulting in (9) [12].

$$
\dot{\mathrm{m}}_{\mathrm{A}}(\mathrm{t})=\frac{4 \mathrm{C}_{\mathrm{AO}} \mathrm{DA}}{\mathrm{L}} \sum_{\mathrm{m}=0}^{\infty} \mathrm{e}^{-\mathrm{D} \beta_{\mathrm{n}}^{\mathrm{x}} \mathrm{t}}
$$

Therefore, the extracted mass of soluble constituent is shown in (10) [12]. 


$$
\mathrm{m}_{\mathrm{A}}(\mathrm{t})=\frac{8 \mathrm{~m}_{\mathrm{AO}}}{\mu^{2}} \sum_{\mathrm{m}=0}^{\infty} \frac{\left(1-\mathrm{e}^{-\frac{(m+1)^{2} \mathrm{~m}^{2} \mathrm{Dt}}{\mathrm{L}^{2}}}\right)}{(2 \mathrm{~m}+1)^{2}}
$$

The degree of extraction is obtained as shown in (11) [12].

$$
\mathrm{e}(\mathrm{t})=\frac{\mathrm{m}_{\mathrm{A}}(\mathrm{t})}{\mathrm{m}_{\infty}}=\frac{\sum_{\mathrm{m}=0}^{\infty} \frac{(1-\mathrm{e}}{\left.\frac{-(2 m+1)^{2} \pi^{2} D t}{L^{2}}\right)}}{\sum_{m=0}^{\infty} \frac{(2 m+1)^{2}}{1}}
$$

\subsection{Hervas et al (2006) method}

Hervas et al (2006) proposed a first-order kinetic mechanism shown as in (12) to study the extraction process under the equilibrium condition [2].The model is also known as pseudo-first order kinetics where no washing of the essential oil occurs. The pseudo-first order kinetics is a logarithmic equation that is frequently used to model both water and steam distillations [15].

$$
\frac{\mathrm{dc}}{\mathrm{dt}}=\mathrm{k}\left(\mathrm{C}_{\mathrm{o}}-\mathrm{C}\right)
$$

Where $\mathrm{C}$ is the amount of essential oil produced, $t$ is the extraction time in hours, $C_{o}$ is the initial essential oil present and $\mathrm{k}$ is the effective diffusion coefficient. (12) is then integrated between the initial moment and a given point at time $t$ to (13) [16].

$$
\mathrm{C}=\mathrm{C}_{0}\left(1-\mathrm{e}^{-\mathrm{kt}}\right)
$$

The simulation of the model is run by using Microsoft Excel programming and the optimum value $k$ is found by using the minimization of the root mean square error (RMSE) shown as in (18).

\subsection{Garkal et al (2012) method}

Garkal et al (2012) proposed a second order rate with the $\mathrm{k}$ is the second-order extraction rate constant. The mathematical model is shown as in (14) [17]. The mathematical model is integrated with the initial boundary condition, $t=0$ to $t$ and $C t=0$ to $C t$ shown as in (15) [17].

$$
\begin{aligned}
& \frac{\mathrm{dC}_{\mathrm{t}}}{\mathrm{dt}}=\mathrm{k}\left(\mathrm{C}_{\mathrm{s}}-\mathrm{C}_{\mathrm{t}}\right)^{2} \\
& \frac{\mathrm{C}_{\mathrm{t}}}{\mathrm{t}}=\frac{1}{\left[\frac{1}{\mathrm{k}} \mathrm{C}_{\mathrm{g}}^{2}\right]+\left[\frac{\mathrm{t}}{\mathrm{C}_{\mathrm{g}}}\right]}
\end{aligned}
$$

Where $C t$ is the mass of oil extracted at time $t, t$ is the extraction time in $C s$ is the initial amount of mass in the plant that is assumed to be the maximum mass of essential oil extracted over time. The simulation of the model is run by using Microsoft Excel programming and the optimum value $k$ is found by using the minimization of the root mean square error (RMSE) shown as in (18). 


\subsection{Ana et al (2007) method}

Ana et al (2007) proposed a second order rate with two k parameter which each represents the washing and diffusion separately. The mathematical model is shown as in (16) where $C(t)$ is the mass of oil produce at time $t, t$ is the extraction time in hours, $C o$ is the initial mass oil of the essential oil at time $t=0$ which usually assumed to be zero, $K 1$ is the extraction rate constant and $K 2$ is the extraction capacity constant [18].

$$
\mathrm{C}(\mathrm{t})=\mathrm{C}_{\mathrm{o}}+\frac{\mathrm{t}}{\mathrm{K}_{1}+\mathrm{K}_{2} \mathrm{t}}
$$

The simulation of the model is run by using Microsoft Excel programming and the optimum value $K 1$ and $K 2$ are found by using the minimization of the root mean square error (RMSE) shown as in (18).

\subsection{Milojevi et al (2008) method}

Milojevi et al (2008) proposed a second order rate with the $\mathrm{k}$ is the second-order extraction rate constant. The mathematical model is shown as in (17). The mathematical model is derived using Fick's second law at unsteady state for one-dimensional rectangle geometry [19].

$$
\frac{q_{0}-q}{q_{0}}=A \cdot e^{-k t}
$$

Where qo represents the essential oil present in the citronella leaves which is assumed to be the maximum oil extracted in the experimental data, $q$ is the essential oil produce at time $t, A$ is a constant and $K$ is the kinetic constant that includes the diffusion coefficient. The simulation of the model is run by using Microsoft Excel programming and the optimum value $A$ and $k$ are found by using the minimization of the root mean square error (RMSE) shown as in (18).

\subsection{Statistical criteria used}

The adequacy of the fit of the models to the experimental data are analyzed by using three statistical criteria that are correlation coefficient $(r)$ shown as in (18) [20], the root mean square error (RMSE) shown in (19) [14], and the mean relative deviation modulus $(E)$ shown in (20) [14] as the application of only one statistical criteria use for observation is not sufficient in evaluating non-linear mathematical model [21]. The model fits the experimental data well when $R M S E \rightarrow 0, r \rightarrow 1$ and $E<10 \%$ [14].

$$
\begin{aligned}
& \text { RMSE }=\sqrt{\frac{1}{\mathrm{~N}} \sum_{\mathrm{i}=1}^{\mathrm{N}}\left(\mathrm{M}_{\text {experiment }, \mathrm{i}}-\mathrm{M}_{\text {predicted }, \mathrm{i}}\right)^{2}} \\
& \mathrm{r}=\frac{\mathrm{n} \sum x \mathrm{x}-\sum \mathrm{x} \sum \mathrm{y}}{\sqrt{\left[\mathrm{n}\left(\sum \mathrm{x}^{2}\right)-\left(\sum \mathrm{x}\right)^{2}\right]\left[\mathrm{n}\left(\sum \mathrm{y}^{2}\right)-\left(\sum \mathrm{y}\right)^{2}\right]}} \\
& \mathrm{E}=\frac{100}{\mathrm{~N}} \sum_{\mathrm{i}=1}^{\mathrm{N}}\left|\frac{\mathrm{C}_{\text {experiment }, \mathrm{i}}-\mathrm{C}_{\text {predicted }, \mathrm{i}} \mid}{\mathrm{C}_{\text {experiment }, \mathrm{i}}}\right|[\%]
\end{aligned}
$$




\section{Result and discussion}

\subsection{Laboratory result}

The experimental data from steam distillation for citronella is shown in Table 1 and the yield of the essential oil extraction as time function is shown in Figure 1 [12].

Table 1. Experimental data from steam distillation for citronella as time function [12].

\begin{tabular}{|c|c|c|c|}
\hline $\begin{array}{c}\text { Time } \\
\text { Extraction } \\
(\mathrm{min})\end{array}$ & $\begin{array}{c}\text { Mass Oil } \\
\text { Extracted (g) }\end{array}$ & $\begin{array}{c}\text { Degree of } \\
\text { Extraction, e }\end{array}$ & Yield \\
\hline 0.0 & 0.0000 & 0.0000 & 0.0000 \\
\hline 3.0 & 0.0850 & 0.0833 & 0.0021 \\
\hline 6.0 & 0.1700 & 0.1667 & 0.0043 \\
\hline 9.0 & 0.3400 & 0.3333 & 0.0085 \\
\hline 12.0 & 0.4250 & 0.4167 & 0.0106 \\
\hline 16.5 & 0.5100 & 0.5000 & 0.0128 \\
\hline 21.0 & 0.5950 & 0.5833 & 0.0149 \\
\hline 25.5 & 0.6800 & 0.6667 & 0.0170 \\
\hline 36.0 & 0.7650 & 0.7500 & 0.0191 \\
\hline 66.0 & 0.8500 & 0.8333 & 0.0213 \\
\hline 90.0 & 0.9350 & 0.9167 & 0.0234 \\
\hline 114.0 & 1.0200 & 1.0000 & 0.0255 \\
\hline
\end{tabular}

It can be seen that in between zero minute to 25 minute the extraction of the citronella essential oil happen rapidly as the gradient of the graph at the early stage is almost linear increase in the cumulative volume of essential oil with time. The extraction of the citronella essential oil started to slows down after 25 minute and increases gradually until 120minute. Although the extraction of the citronella essential oil increases rapidly during the first 25 minutes, the extraction is not in linear and uniformly order. This is probably due to the variations in the heat supplied to the water boiler thus affecting the amount of steam supply to the extraction chamber.

By the increases of extraction time, the amount of oil extracted also increases until 0.019125 $\mathrm{g} / \mathrm{g}$ yield at 36 minutes. Further increase in the extraction time result in not significant increases in the amount of oil extracted. Through the experimental result obtained, it is confirm that the kinetics of the diffusion in extraction of citronella essential oil obeys the Fick's second law of diffusion which follows the pattern after a certain time, the solute concentration in the citronella and the steam solvent achieve final equilibrium [22].

Thus the extraction of the citronella essential oil can be divided into two processes that are washing process and dissolve process. Washing phase refers to the fast phase where initial increase is caused by quick dissolution of easily accessible solute from the plant cell into the steam solvent [14]. The increase in temperature due to the steam supplied to the plant increases the pressure within the plant cell containing the essential oil. When the pressure reached certain level, the cell membrane breaks thus releasing the essential oil [15].

The washing process occurs when the external cell on the plant surface start to break thus releasing the essential oil. This process occurs almost instantaneously and in fast period of time. The essential oil from the internal cell of the plant must diffuse from the interior of the plant particle to the plant external surface. This process known as diffusion process where it occurs more slowly after the washing phase has completed [15]. 


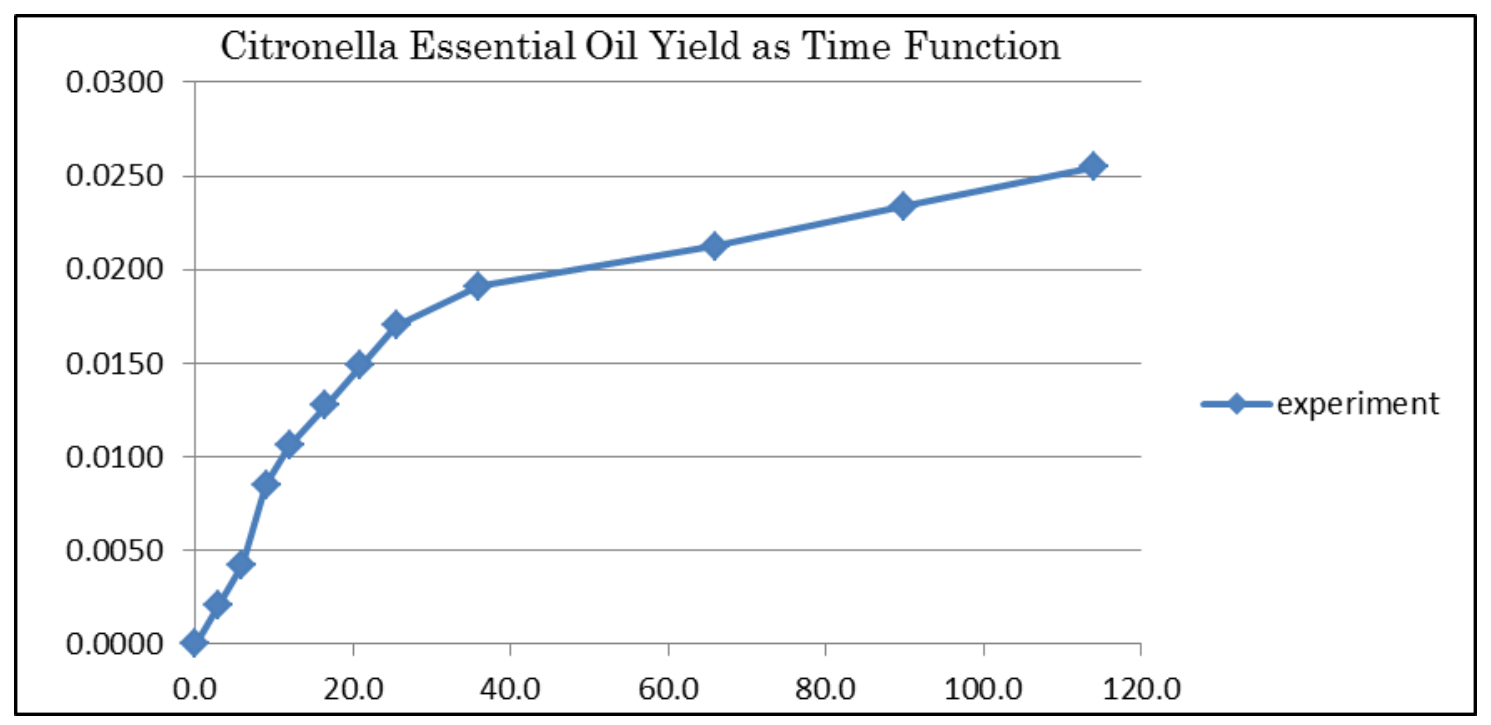

Figure 1: Citronella experimental yield as time function (Cassel and Vargas, 2006).

\subsection{Cassel and Vargas (2006) method}

Cassel and Vargas (2006) proposed optimum parameter $D 1.60 \times 10^{-11}$. This parameter was estimated using the minimization of sum of square of errors between the experimental data and the prediction from the model. The minimum value is found by using Nelder- Mead Simplex method with software Matlab version 6. The result of the simulation is shown in Figure 2.

From Figure 2 shown, it can be clearly seen that the mathematical model and parameter $D$ value proposed by Cassel and Vargas (2006) does not have the perfect fit in predicting the citronella essential oil yield extracted over time. The RMSE error calculated is $31.79 \%$ showing the differences between the experimental result and the prediction made by the mathematical model. This probably due to the assumption made at the early stage where parameter $D$ is assumed to be constant overtime whereby in the experiment conducted in the laboratory scale, two process in the extraction was identified that are washing process and diffusion process. The mathematical model also does not take into account the resistance occurs in diffusion of essential oil from the interior of the plant to the external surface of the plant.

The mathematical model proposed by Cassel and Vargas (2006) is further optimized by finding the optimum parameter $D$ value. The new optimum value of parameter $D$ is found by using the minimization of the root mean square error (RMSE) shown in (18). The new optimum value of parameter $D$ found by using the solver is $5.4 \times 10^{7}$. The predicted mass essential oil extracted and yield is shown in Figure 3.

By comparing the data on Figure 2 and Figure 3, we can observe a significant improvement in the mathematical model with the reduction of $R M S E$ error from $31.79 \%$ to $22.61 \%$ after the parameter $D$ is optimized. Nevertheless, the mathematical model still failed to predict the extraction of the essential oil after the washing stage and does not fit the experimental data perfectly. This confirms the assumption on the error made earlier where parameter $D$ is assumed to be constant overtime does not take into account the resistance occurs in diffusion of essential oil from the interior of the plant to the external surface of the plant thus limiting the ability of the mathematical model to predict the amount of citronella oil extracted over time. 


\subsection{Hervas et al (2006) method}

The simulation of the model is shown in Figure 4 and the optimum value $k(0.04)$ is found by using the minimization of the root mean square error (RMSE) shown in (18). Correlation coefficient $(r)(0.3602)$ and the mean relative deviation modulus $(E)$ (4.5204) are found using (19) and (20).

\subsection{Garkal et al (2012) method}

The simulation of the model is shown in Figure 5 and the optimum value $k(0.06292)$ is found by using the minimization of the root mean square error $(R M S E)$ shown in (18) .Correlation coefficient (r) (09923) and the mean relative deviation modulus $(E)$ (17.92) are found using (19) and (20).

\subsection{Ana et al (2007) method}

The simulation of the model is shown in Figure 6 and the optimum value $K 1$ (19.09) and $K 2$ (0.8301) are found by using the minimization of the root mean square error (RMSE) shown in (18). Correlation coefficient $(r)(0.9943)$ and the mean relative deviation modulus $(E)(11.5183)$ are found using (19) and (20).

\subsection{Milojevic et al (2007) method}

The simulation of the model is run shown in Figure 7 and the optimum value $A(1.003)$ and $k$ $(0.0402)$ are found by using the minimization of the root mean square error (RMSE) shown in (18). Correlation coefficient $(r)(0.9931)$ and the mean relative deviation modulus $(E)(9.0641)$ are found using (19) and (2

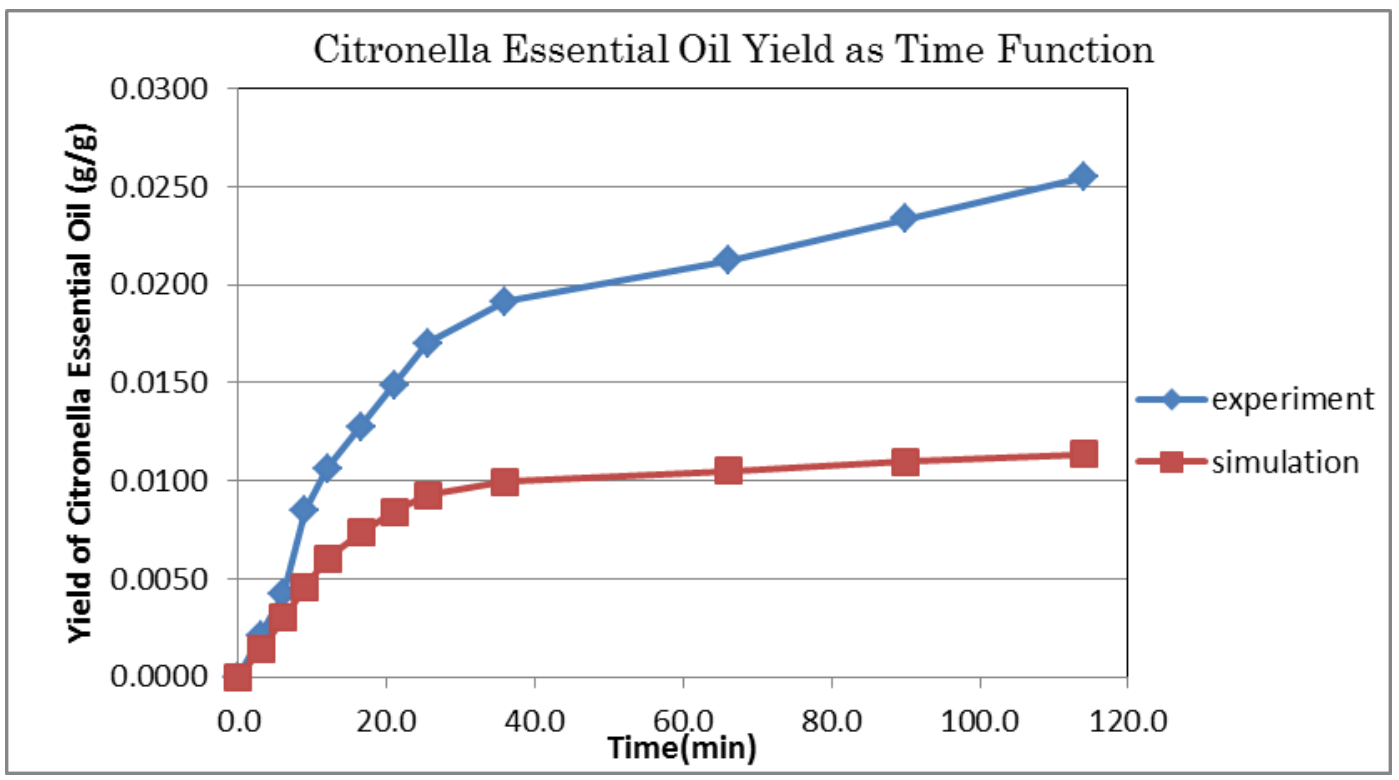

Figure 2. Cassel and Vargas citronella essential oil predicted yield as time function 


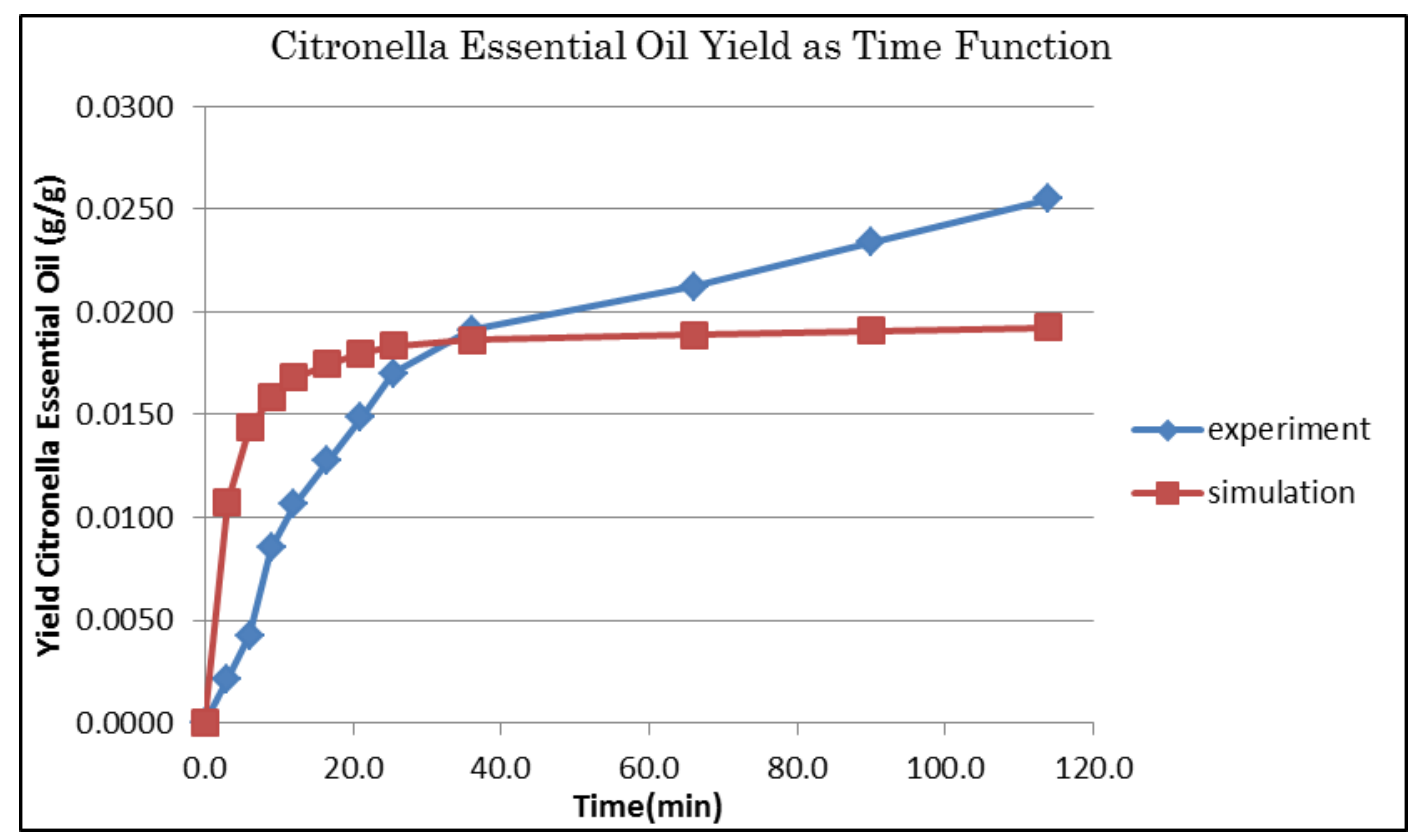

Figure 3. Optimized Cassel and Vargas citronella essential oil predicted yield as time function

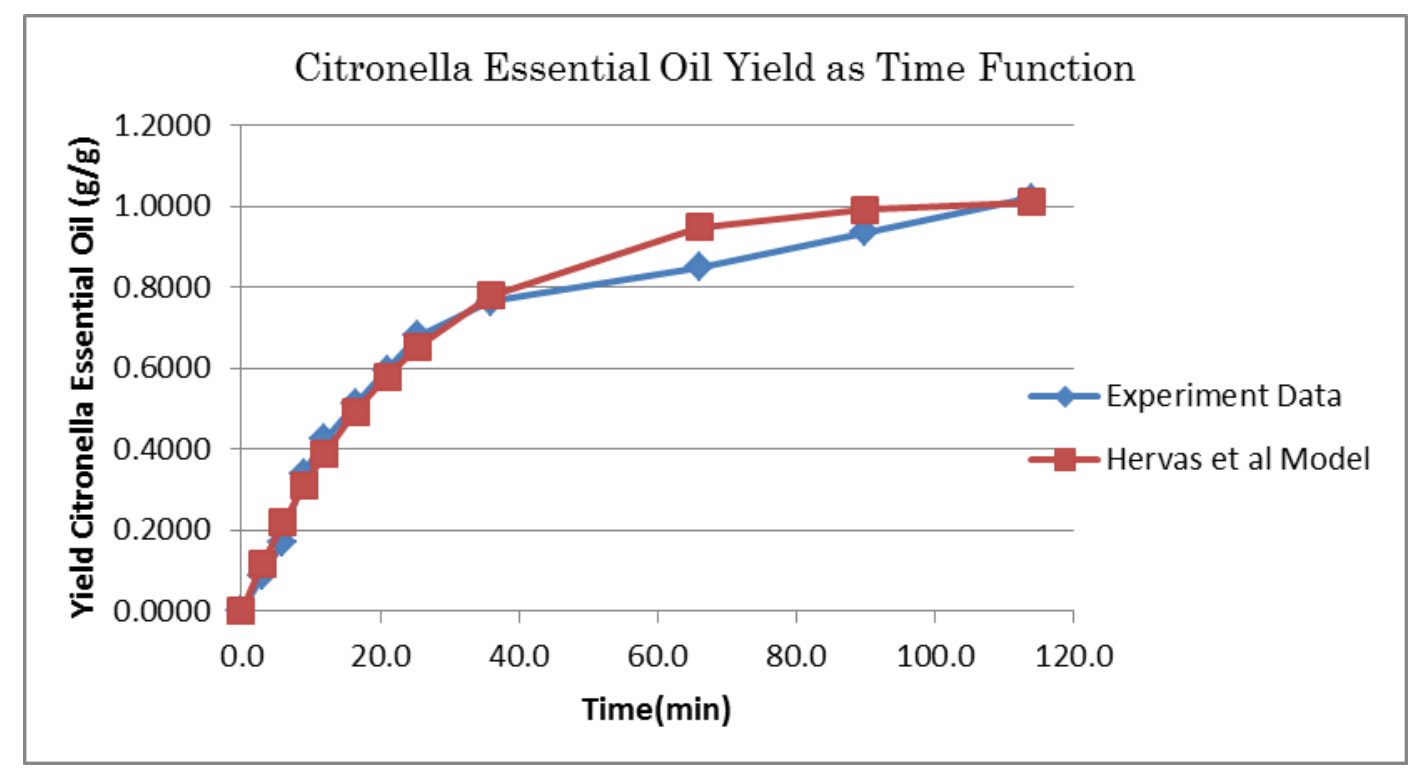

Figure 4. Hervas et al (2006) mathematical model predicted mass oil extracted as time function 


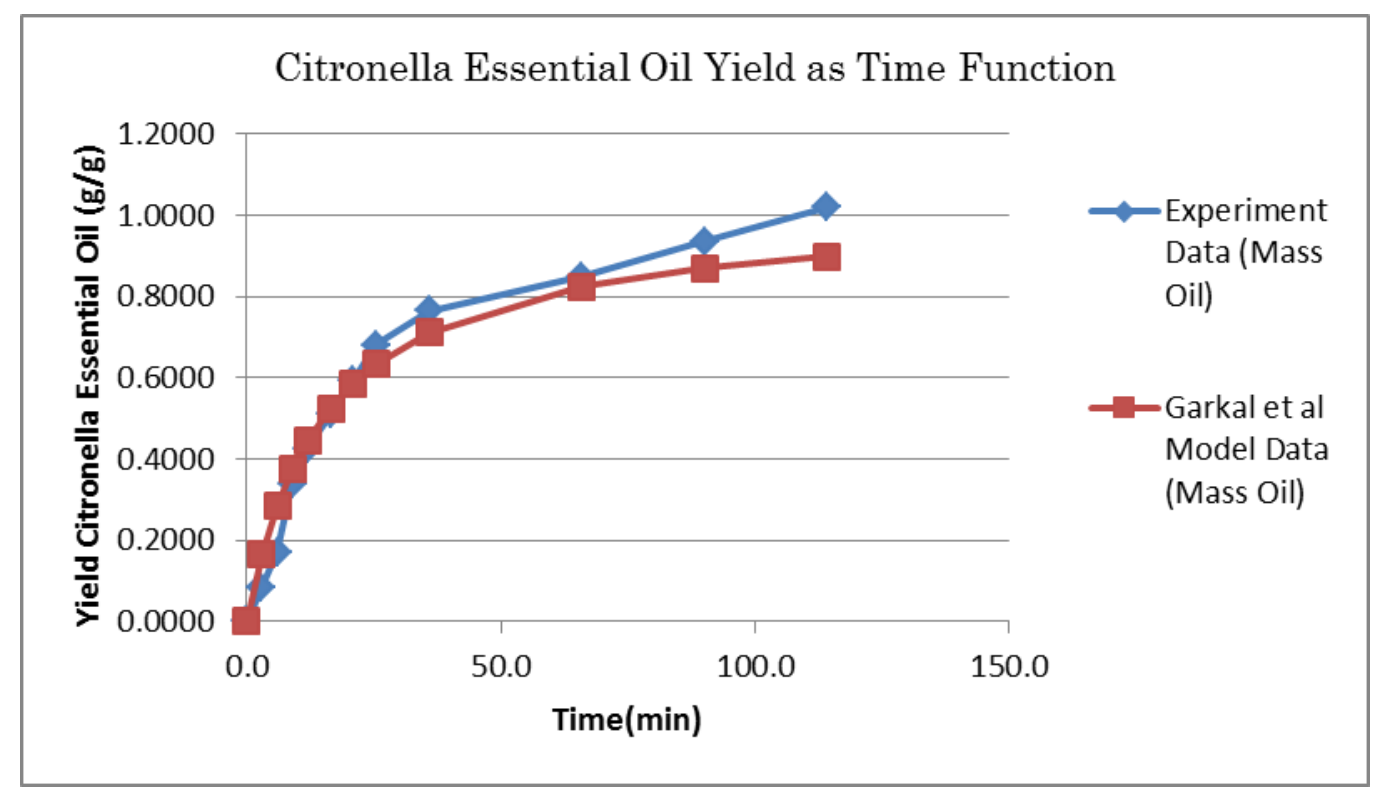

Figure 5. Garkal et al (2012) mathematical model predicted mass oil extracted a as time function

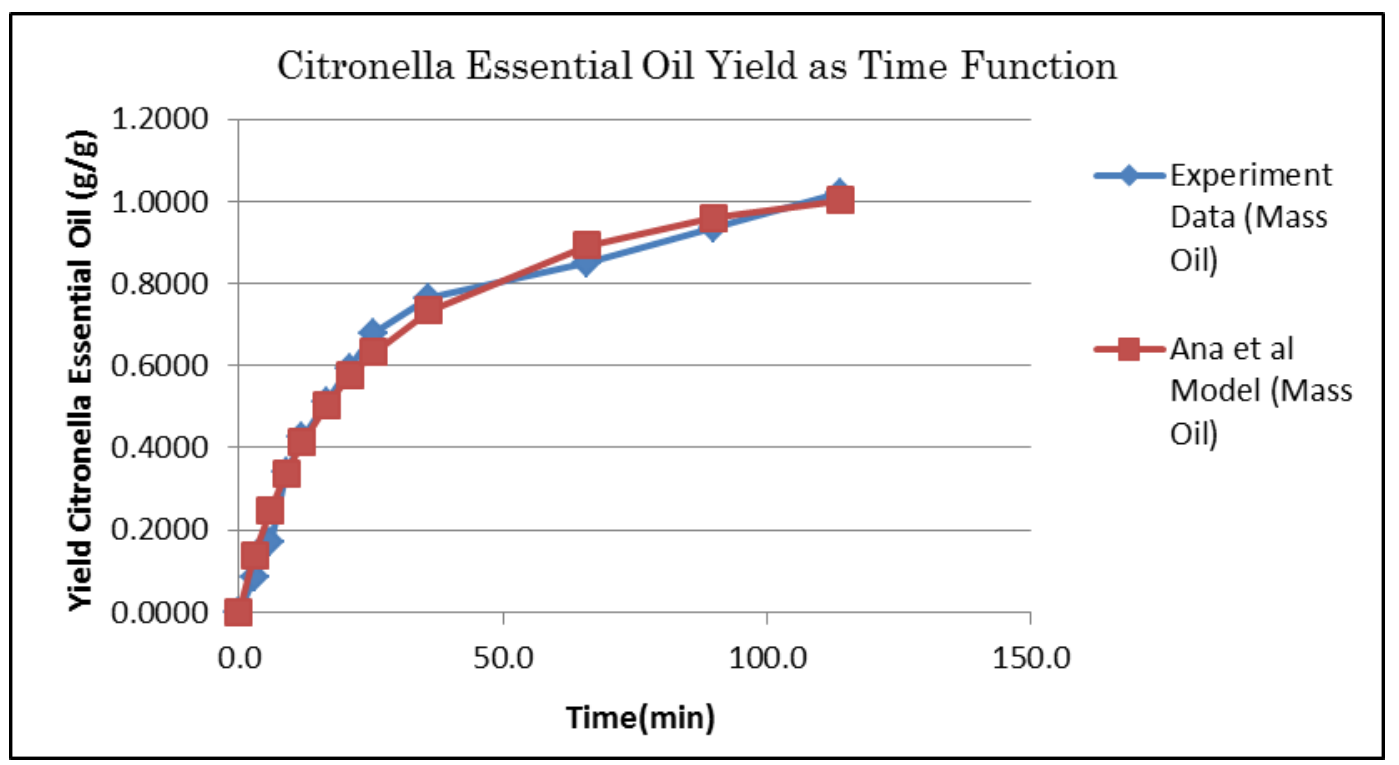

Figure 6. Ana et al (2007) mathematical model predicted mass oil extracted as time function 


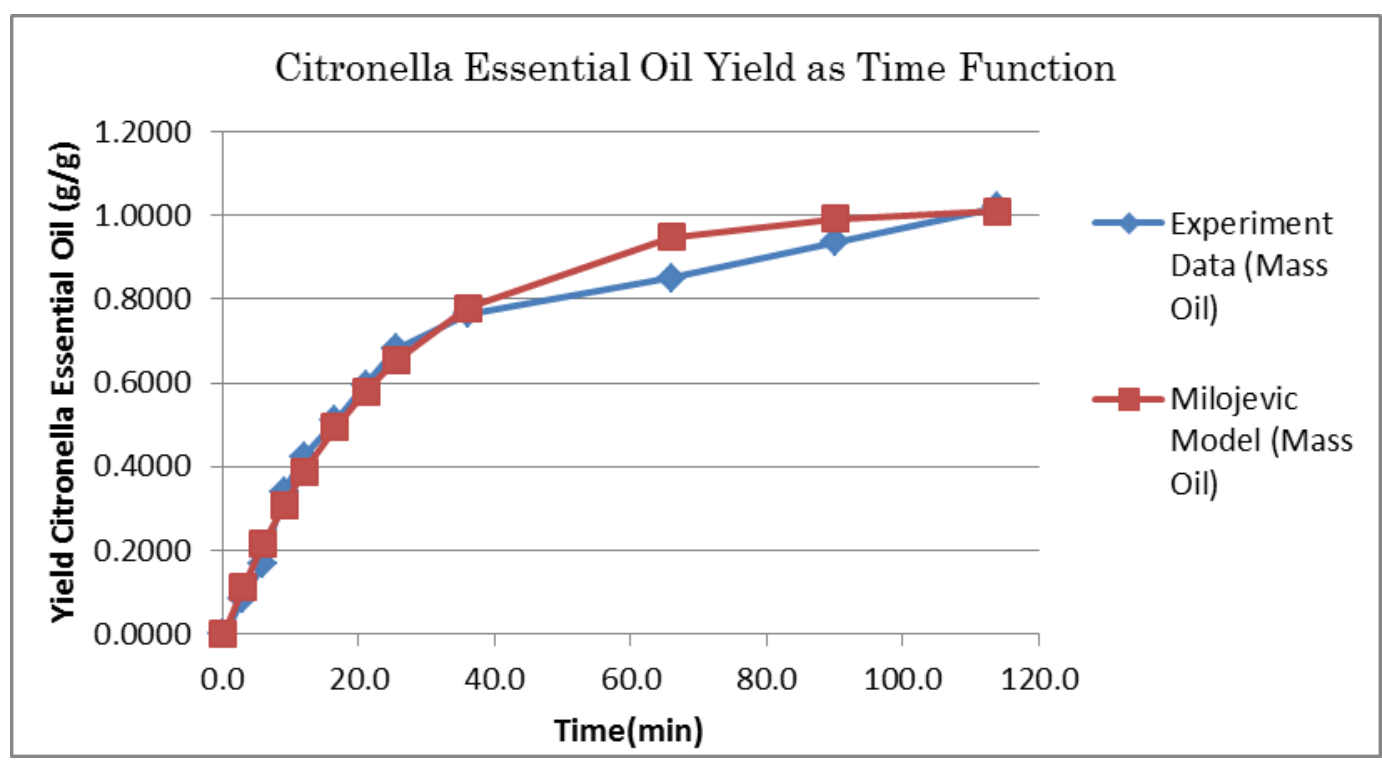

Figure 7. Milojevic et al (2008) Mathematical Model Predicted Mass Oil Extracted as Time Function

\subsection{Statistical criteria result}

The proposed mathematical model and parameter $D$ value by Cassel and Vargas (2006) does not have the perfect fit in predicting the citronella essential oil yield extracted over time. The RMSE error calculated for the mathematical model and parameter $D$ value proposed is $0.317916(31.79 \%$ error). By optimizing the value of parameter $D$ by using the minimization of the root mean square error $(R M S E)$ as shown in (18) and Microsoft Excel Solver, the new optimum parameter $D$ value is $5.4 \mathrm{x} 10^{7}$. Nevertheless the $R S M E$ error calculated is still very high 0.226 (22.6\% error).

Table 2. Statistical Criteria Result

\begin{tabular}{|l|c|c|c|c|}
\hline Model & RMSE & RMSE $(\%)$ & $\mathrm{r}$ & $\mathrm{E}(\%)$ \\
\hline Hervas et al $(2006)$ & 0.0424 & 4.2435 & 0.3602 & 4.5204 \\
\hline Garkal et al $(2012)$ & 0.0647 & 6.4662 & 0.9923 & 17.9200 \\
\hline Ana et al $(2007)$ & 0.0377 & 3.7713 & 0.9943 & 11.5183 \\
\hline Milojevi et al $(2008)$ & 0.0424 & 4.2414 & 0.9931 & 9.0641 \\
\hline Best Model & $\begin{array}{c}\text { Ana } \text { et al } \\
(2007)\end{array}$ & $\begin{array}{c}\text { Ana } \text { et al } \\
(2007)\end{array}$ & $\begin{array}{c}\text { Ana } \text { et al } \\
(2007)\end{array}$ & $\begin{array}{c}\text { Hervas } \text { et al } \\
(2006\end{array}$ \\
\hline
\end{tabular}

Thus to find the most optimum mathematical model for Cymbopogon winterianus Essential Oil Extraction by Steam Distillation, four mathematical models consist of first order kinetic and second order kinetic is studied. The mathematical models being studied are mathematical model proposed by Hervas et al (2006) Method, Garkal et al (2012) Method, Ana et al (2007) Method and Milojevi et al (2008) Method. Three criteria that are correlation coefficient $(r)$, the root mean square error $(R M S E)$ and the mean relative deviation modulus $(E)$ is used in determining the most adequacy of the fit of the models to the experimental data as shown in Table 2. Ana et al (2007) Method had satisfied two of the criteria with the most minimum value of RMSE (3.7713\%) and highest $r$ value (0.9933). However the $E$ value of $11.52 \%$ which are higher than $10 \%$ requirement. This can be improves by further optimization of the model in the future. 


\section{Conclusion}

The research is conducted to find the suitable mathematical model in predicting the Cymbopogon winterianus essential oil extraction by steam distillation. The research is a continuation of Cassel and Vargas (2006) previous research "Experiments and Modelling of the Cymbopogon winterianus Essential Oil Extraction by Steam Distillation". The proposed optimum D parameter value in the previous research is used to simulate and verify the prediction value of the mathematical model. Laboratory scale experiment data in previous research done by Cassel and Vargas (2006) in their research "Experiments and Modelling of the Cymbopogon winterianus Essential Oil Extraction by Steam Distillation" were used as a benchmark and reference.

From the research, it is found that the mathematical model proposed by Cassel and Vargas (2006) does not have the perfect fit in predicting the citronella essential oil yield extracted over time. The RMSE error calculated for the mathematical model and parameter $D$ value proposed is 0.317916 (31.79\% error). By further optimizing the mathematical model, a new value of parameter $D$ was proposed and the $R M S E$ value reduces to 0.226 ( $22.6 \%$ error). Thus the objective to optimize the mathematical model minimum of 5\% was achieved. Nonetheless the value of the RMSE error for the optimized mathematical model is still very high and more than $10 \%$ error in predicting the extraction process. This is due to the assumption the made earlier when developing the mathematical model where parameter $D$ is assumed to be constant overtime and does not take into account the resistance occurs in diffusion of essential oil from the interior of the plant to the external surface of the plant.

Thus, in order to optimize the prediction of essential oil, four new mathematical models developed by Hervas et al (2006) Method, Garkal et al (2012) Method, Ana et al (2007) Method and Milojevi et al (2008) Method were studied. The adequacy of the fit of the models to the experimental data are analyzed by using three statistical criteria that are correlation coefficient $(r)$, the root mean square error (RMSE) and the mean relative deviation modulus (E). The model fits the experimental data well when $R M S E \rightarrow 0, r \rightarrow 1$ and $E<10 \%$. Ana et al. (2007) Method had satisfied two of the criteria with the most minimum value of RMSE (3.7713\%) and highest $r$ value (0.9933). However the $E$ value of $11.52 \%$ which are higher than $10 \%$ requirement. This can be improves by further optimization of the model in the future.

The analysis of the result from the optimization indicates that the mathematical model developed by Ana et al (2007) based on mass transfer fundamentals fitted very well the experimental data. The mathematical model is based on second order rate with two $\mathrm{k}$ parameter which each represents the washing and diffusion separately. The hypothesis used in developing the mathematical model is more coherent with the reality observed while the mathematical model developed by Cassel and Vargas (2006) based on the theory of diffusional model and Fick's Law in steady-state for onedimensional rectangle geometry is more restrictive to describe the steam distillation process of extraction of Cymbopogon winterianus essential oil.

\section{Acknowledgements}

The author would like to express her highest gratitude and sincerest appreciation to supportive and helpful supervisor, Mr Mohd Farid Atan for his constant assistance, guidance and patience in helping the author in completing this research project. The author would also like to express her pleasure to all the staff from Department Chemical Engineering and Energy Sustainability, friends and all individuals' that have contributed and cooperated throughout in completing this project. 


\section{References}

[1] Shasany, A.K., Lal, R.K., Patra, N.K., Darokar, M.P., Garg, A., Kumar, S., and Khanuja, S.P.S., (2000). Phenotypic and RAPD diversity among Cymbopogon winterinus Jowitt accessions in relation to Cymbopogon nardus Rendle. Genetic Resource and Crop Evolution. 47; 553-559.

[2] Peng, T.Y., Don, M.M, and Tahrel, M.A., (2012). Optimisation and kinetics studies on the extraction of essential oil from Zingiber Cassumunar. Journal of Physical Science. 23(1) 65-82.

[3] Tajidin, N.E., Ahmad, S.H., Rosenani, A.B., Azimah, H., and Munirah, M., (2012). Chemical composition and citral content in lemongrass (Cymbopogon citrates) essential oil at three maturity stages. African Journal of Biotechnology. 11(11), 2685-2693.

[4] Yusof, N., (2010). Study of Cymbopogon Citratus (Lemongrass) essential oil extraction technique, B.Che.E., Universiti Malaysia Pahang, Malaysia.

[5] Kabuba, J.T., (2009). Steam extraction of essential oils: Investigation of process parameter, B.Che.E., University of Johannesburg. South Africa.

[6] Amenaghawon, N.A., Okhueleigbe, K.E., Ogbeide, S.E., and Okieimen, C.O., (2014). Modelling the kinetics of steam distillation of essential oil from lemon grass (cymbopogon spp). International Journal of Applied Science and Engineering. 12(2), 107-115.

[7] Koul, V.K., Gandotra, B.M., Ghosh, S., Tikoo, C., L., and Gupta, A.K., (2003). Steam distillation of lemon grass (Cymbopogon spp.). Indian Journal of Chemical Technology. 11; 135-139.

[8] Sugumaran, M., Joseph, S., Lee, K.L.W., and Wong, K.W., (2005). Herbs of Malaysia. Federal Publication, Shah Alam, Malaysia.

[9] Cassel, E., Vargas, R.M.F, Martinez, N., Lorenzo, N., and Dellacassa, E., (2008). Steam distillation modelling for essential oil extraction. Industrial Crops and Products. 29; 171-176.

[10] Pornpunyapat, J., Chetpattananondh, P., Tongurai, C., (2011). Mathematical modelling for extraction of essential oil from Aquilaria crassna by hydro distillation and quality of agarwood oil. Bangladesh Journal of Pharmacol. 6; 18-24.

[11] Benyoussef, E. H., Hasni, S., Belabbes, R., and Bessiere, J. M., (2002). Modelling of mass transfer during extraction of the essential oil of coriander fruits. Chemical Engineering Journal, 85(1): 1-5.

[12] Cassel, E., and Vargas, R.M.F., (2006). Experiments and modelling of the Cymbopogon winterianus essential oil extraction by steam distillation. Journal of the Mexican Chemical Society, 50(3): 126-129

[13] Ha, H.K.P., Maridable, J., Gaspillo, P., Hasika, M., Malaluan, R., and Kawasaki, J., (2010). Modelling and Optimization of Supercritical Carbon Dioxide Extraction on Essential Oil from Lemongrass using Response Surface Methodology. Journal of Research in Science, Computing, and Engineering, 4(3): 1-10.

[14] Ana, B.K., Sovova, H., Planinic, M., and Tomas, S., (2013). Temperature-dependent kinetics of grape seed phenolic compounds extraction:Experiment and model. Food Chemistry. 136; 1136-1140.

[15] Milojevi, S., Radosavljevic, D.B., Pavicevic, V.P., Pejanovic, S., and Veljkovic, V.B., (2013). Modelling the kinetic of essential oil hydro distillation from plant material. Hem.ind. 67(5), 843-859.

[16] Hervas, F.F., Serra, P.C., Torres, C.B., Pernandez, M.P., Gratacos, D.Q., (2006). Study of the extraction kinetic of glycosaminoglycans from raw sheepskin trimmings. Proceedings of International United of Environment Commission of IULTCS, Chengdu, China, 14-16 October.

[17] Garkal, D.J., Taralkar, S.V., Kulkarni P., Jagtap S., and Nagawade A., (2012). Kinetic model for extraction of eugenol from leaves of ocimum sanctum linn (Tulsi). International Journal of Pharmaceutical Applications. 3(1), 267-270.

[18] Ana, B.K., Mirela, P., Srecko, T., Mate, B., and Darko, V., (2007). Study of solid-liquid extraction kinetics of total polyphenols from grape seeds. Journal of Food Engineering, 81: 236-242.

[19] Milojevi, S.Z., Stojanovi, T.D., Palic, R., Lazic, M.L., and Veljkovic, V.B., (2008). Kinetics of distillation of essential oil from comminuted ripe juniper (Juniperus communis L.) berries. Biochemical Engineering Journal. 39:547-553. 
[20] Yount, R., (2006). Research Design and Statiscal Analysis in Christian Ministry. Published by NAPCE, Texas, USA.

[21] Kashaninejad, M., Mortazavi, A., Safekordi, A., and Tabil, L.G., (2007). Thin-layer drying characteristic and modelling of pistachio nuts. Journal of Food Engineering. 78; 98-108.

[22] Hazwan, M.H, Hasfaline, H., Hishamuddin, C.M., and Zurina Z.A., (2012). Optimization and kinetics of essential oil extraction from citronella grass by ohmic heated hydro distillation. International Journal of Chemical Engineering and Application. 3(3) 173-177. 


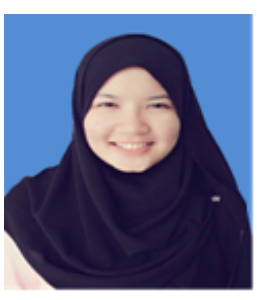

\begin{abstract}
Authors
Nik 'Amirah Farhana Nik Ahmad Lutfi

Nik 'Amirah Farhana Nik Ahmad Lutfi was a graduate in Department of Chemical Engineering and Energy Sustainability, Faculty of Engineering, Universiti Malaysia Sarawak (UNIMAS). She received her B.Eng (Hons) in Chemical Engineering from UNIMAS and currently working as a process engineer in solar industry.
\end{abstract}

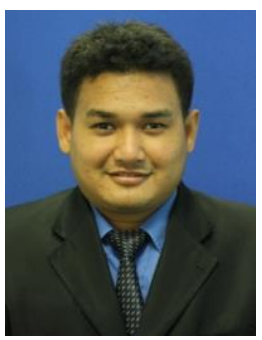

\title{
Mohd Farid Atan
}

Mohd Farid Atan is a Lecturer at Department of Chemical Engineering and Energy Sustainability, Faculty of Engineering, Universiti Malaysia Sarawak (UNIMAS). He received his M.Eng Diploma in Chemistry and Process Engineering from ESCPE Lyon, France. His areas of specialization are chemical processing and wastewater treatment.

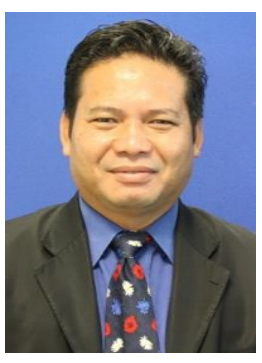

\section{Nazeri Abdul Rahman}

Nazeri Abdul Rahman is a Senior Lecturer at Department of Chemical Engineering and Energy Sustainability, Faculty of Engineering, Universiti Malaysia Sarawak (UNIMAS). He received his M.Eng in Thermal Power and Fluid Engineering from UMIST. His areas of specialization are renewable energy.

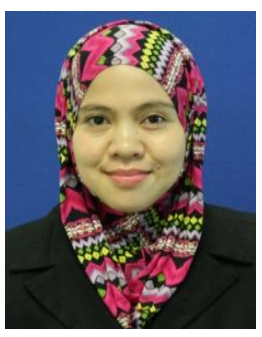

\section{Shanti Faridah Salleh}

Shanti Faridah Salleh is a Senior Lecturer at Department of Chemical Engineering and Energy Sustainability, Faculty of Engineering, Universiti Malaysia Sarawak (UNIMAS). She received her PhD in Chemical Engineering from Universiti Putra Malaysia (UPM). Her areas of specialization are renewable energy.

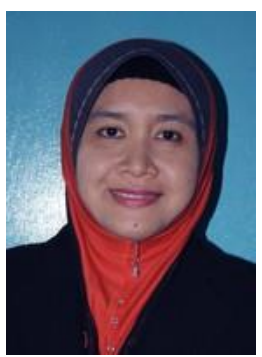

\section{Noraziah Abdul Wahab}

Noraziah Abdul Wahab is a Lecturer at Department of Chemical Engineering and Energy Sustainability, Faculty of Engineering, Universiti Malaysia Sarawak (UNIMAS). She received her Master in Chemical Engineering from Universiti Malaysia Sarawak (UNIMAS). Her areas of specialization are wastewater treatment. 